Methods: We studied a one and a half-year period, from June 2018 to December 2019. During this time, 57 applications were submitted to participate in the courses. All participants who arrived were tested before starting the course. Test included 40 general questions about MSUS. Test results as well as commitment to training were analyzed in two groups: rheumatologists and radiologists. Nonparametric statistics were used for data processing.

Results: Among 57 applications submitted for the courses, 26 were from rheumatologists and 31 from radiologists, but the courses were attended by 13 rheumatologists and 26 radiologists (68\%). Thus, commitment was reliably higher in radiologists (84\%) than in rheumatologists $(50 \%)$. Fisher's methods show high statistically significance $\left(X^{2}=7,51, p=0,006\right)$. Although the test focused on ultrasound, it was surprise for us that the median percentage of correct answers was higher in rheumatologists - $64(54 ; 80) \%$, than radiologists ("ultrasonography specialists") $48(40 ; 62) \%$. Difference also were significantly $(p=0,04)$.

Conclusion: Thus, despite better preparedness of rheumatologist, motivation to study MSUS prevails among radiologists. It is necessary to actively introduce MSUS into general rheumatologic educational programs in order to motivate rheumatologists to study MSUS. Changes in professional standard will also encourage wide use of MSUS by rheumatologists.

Disclosure of Interests: None declared

DOI: 10.1136/annrheumdis-2020-eular.6158

\section{THU0646-HPR EXPLORING THE ROLE OF NURSE IN RHEUMATIC CARE AND FEASIBILITY OF ENHANCING TREAT TO TARGET STRATEGIES IN JAPAN.}

M. Fusama ${ }^{1,2}$, M. Uda ${ }^{3}$, H. Matsumura ${ }^{4}$, Y. Van Eijk-Hustings ${ }^{5}$, S. Oliver ${ }^{6}$, H. Nakahara 2. ' Yukioka Hospital, Osaka, Japan; ${ }^{2}$ Osaka Yukioka College of Health Science, Osaka, Japan; ${ }^{3}$ Kyoto College of Nursing, Kyoto, Japan; ${ }^{4}$ Higami Internal Medicine Rheumatism and Daibetes, Nara, Japan; ${ }^{5}$ Department of Patient \& Care/Clinical Epidemiology and Medical Technology Assessment (KEMTA), Maastricht, Netherlands; ${ }^{6}$ Susan Oliver Associates, London, United Kingdom

Background: The role of rheumatology nurses is considered important for the implementation of T2T [1]. For nurses' contribution to implementation of the T2T strategy, it is necessary to explore the nurses' opinion on their roles in real clinical practice.

Objectives: The aim of this study is to evaluate what is required for nurses to implement T2T in real clinical practice in Japan.

Methods: Registered nurses engaged in rheumatic care in clinical practice in Japan were enrolled. Focus group interviews were conducted exploring 'What is necessary for RA nurses to implement T2T'using semi-structured interviews. Data analysis was used with Krippendorff's content analysis method.

Results: 24 nurses (all females) from 10 hospitals were enrolled in this study. The results of the qualitative analysis were categorized in 10 main categories, derived from 37 subcategories based on 64 different codes: (1) provide basic knowledge of RA, (2) provide knowledge of RA drugs, (3) provide knowledge and skills of self-monitoring, (4) enhance self-efficacy and support self-management, (5) support decision-making, (6) psychological and social support, (7) understand the diversity and feelings of patients and their families, (8) support based on individual needs, (9) ensure continuing educational opportunities for nurses to enable the provision of high quality care, (10) collaborate with multidisciplinary teams.

These categories are mostly covered in the contents of the 2018 updated EULAR recommendations for the role of nurses except "evidence-based rheumatic care", "telehealth" and "comprehensive participation in disease management".

Conclusion: These findings indicate the areas of exploration including further educational and training needs, attitudes and the professional scope for nurses to extend their roles to provide greater value to patient care.

In Japan, evidence-based RA nursing and telehealth systems have not yet been established. In addition, therapeutic intervention by nurses and nurse-led clinic are not permitted. Our results might reflect this situation and possibly elucidates the gap between EULAR's evidence-based recommendations and opinions of Japanese nurses working in daily clinical practice. As evidence-based nursing is considered to be crucial from both cost-effectiveness and improvement of patients QOL, this result also might shed light on what we need for future better rheumatic nursing in Japan.

References:

[1] van Eijk- Hustings $Y$, et al. Ann Rheum Dis 2012;71: 13-19.

Disclosure of Interests: MIE FUSAMA: None declared, Miyabi Uda: None declared, Harumi Matsumura: None declared, Yvonne van Eijk-Hustings Grant/ research support from: grand from sanofi and UCB, Consultant of: fee from amgen, Susan Oliver: None declared, Hideko Nakahara: None declared DOI: 10.1136/annrheumdis-2020-eular.5315

\section{THU0647-HPR SHARED DECISION MAKING AMONGST RHEUMATOLOGISTS IN TRAINING IN THE NETHERLANDS: WHERE DO WE STAND?}

L. Kranenburg ${ }^{1}$, M. Dankbaar ${ }^{2}$, N. Basoski ${ }^{3}$, W. Van den Broek ${ }^{2}$, J. Hazes' ${ }^{1}$. ${ }^{1}$ Erasmus MC, Rheumatology, Rotterdam, Netherlands; ${ }^{2}$ Erasmus MC, Institute for Medical Education Research Rotterdam, Rotterdam, Netherlands; ${ }^{3}$ Maasstad hospital, Rheumatology, Rotterdam, Netherlands

Background: The training curriculum for rheumatologists in training in the Netherlands describes competences and entrusted professional activities (EPA) to monitor the progress in learning. However, this training program does not discuss training of Shared Decision Making. As the basis for shared care and patient participation is made during these years, the question arises how rheumatologist in training think about Shared Decision Making and how they use this in daily practice.

Objectives: Inventory of vision, experience and self-evaluation of skills related to Shared Decision Making amongst rheumatologists in training in the Netherlands in order to identify barriers in the implementation of Shared Decision Making in daily practice.

Methods: Qualitative data was collected from on online survey amongst rheumatologists in training who were registered in January 2018 by the Dutch Society of Rheumatology.

Results: Forty-two rheumatologists in training from various years of training responded (60\%). Respondents think that Shared Decision Making is important. A third applies Shared Decision Making on a regular basis in daily practice. Self rating of skills for Shared Decision Making varies from sufficient to good. However, respondents are uncertain about their performance due to a lack of feedback and unclearness of the concept. They indicate that Shared Decision Making is not possible for all patients and find it difficult to assess whether the patient has a clear understanding of the options. Patient's preferences are discussed only by $33 \%$ of the doctors on a regular basis when starting new treatment.

Conclusion: Rheumatologists in training agree on the importance of Shared Decision Making, but are uncertain about their performance. Unclearness of the concept is described as a known barrier in literature ${ }^{1,2}$ and is frequently mentioned by respondents. Rheumatologist in training indicate that not all patients are fit for Shared Decision Making. Regarding the limited training on the subject this could also be a misjudgment of patients preferences and lack of experience how to deal with different patient types. There is a clear plea for more training and feedback on the subject. Training should be integrated in the curriculum focusing on how to assess patients preferences and how to apply Shared Decision Making also for patients who indicate to leave decisions up to their doctor.

References:

[1] van Veenendaal, $\mathrm{H}$. et al. Accelerating implementation of shared decision-making in the Netherlands: An exploratory investigation. Patient Educ Couns 101, 2097-2104 (2018).

[2] Legare, F., Ratte, S., Gravel, K. \& Graham, I. D. Barriers and facilitators to implementing shared decision-making in clinical practice: update of a systematic review of health professionals' perceptions. Patient Educ Couns 73, 526-535 (2008).

Disclosure of Interests: Laura Kranenburg Grant/research support from: Pfizer and UCB for the development of the Reuma App, a tool to support selfmanagement for patients. This is not used for the research related to the submitted abstract., Mary Dankbaar: None declared, Natalja Basoski: None declared, Walter Van den Broek: None declared, Johanna Hazes: None declared DOI: 10.1136/annrheumdis-2020-eular.4142

\section{THU0648-HPR STUDY OF PAIN ATTITUDES \& BELIEFS BETWEEN RHEUMATOLOGISTS, PHYSICAL THERAPISTS AND PATIENTS FOR FIBROMYALGIA- A CROSS- SECTIONAL SURVEY}

S. K. Paramasivam ${ }^{1,2}$, C. S. Kumar ${ }^{2}$ on behalf of Chronic Pain Research Group of Academy of Orthopaedic Manual Physical Therapists (AOMPT). ${ }^{1}$ Academy of Orthopaedic Manual Physical Therapists (AOMPT), Bethel Medical Mission, Physiotherapy, Bengaluru, India; ${ }^{2}$ Bethel Medical Mission, Physiotherapy, Bengaluru, India 
Background: Attitudes and beliefs about pain determine the interpersonal interaction in evaluation and treatment of a chronic painful condition like fibromyalgia in a multidisciplinary healthcare system. Two distinct dimensions for pain attitudes and beliefs were identified as Biomedical and Behavioral. The former utilized a pathoanatomical model whereas the latter incorporated the psychosocial factors into clinical presentations.

Objectives: The study aimed to evaluate the pain attitudes and beliefs amongst rhematologists, physical therapists and fibromyalgia patients and to compare the biomedical and behavioral dimensions between the three groups in study population of fibromyalgia syndrome (FMS).

Methods: A nation-wide cross-sectional survey (online and direct interviews) was conducted between 2010-16 to identify first group- 18 (16 male, 2 female) rheumatologists (snowball sampling), and second group- 122 (44 male, 78 female) physical therapists (purposive sampling), both with previous experience of treating adults with fibromyalgia. Also 188 patients with FMS were also studied from outpatient departments of tertiary care hospitals as the third group. All participants filled the Pain Attitudes and Beliefs (PABS) scale and the scores were analysed to identify the two dimensions descriptively in percentiles, and their between-group comparisons were done using Chi-Square test at 95\% confidence interval using SPSS version 22 for Windows software.

Results: There was an overall predominance of biomedical dimension for FMS reported in all three groups, with rheumatologists being most prevalent $(76.8 \%)$, followed by patients $(65.6 \%)$ and then by physical therapists $(54.12) \%$. Betweengroup comparisons were significant $(p<.05)$ for all 6 analyses.

Conclusion: Biomedical dimension was predominantly reported by rhematologists, physical therapists and patients for chronic pain in FMS and this necessitates further research on development and implementation of educational interventions in this part of the world.

References:

[1] Kumar SP, Jim A. Physical therapy in palliative care: from symptom control to quality of life: a critical review. Indian J Palliat Care. 2010;16(3):138-46.

[2] Kumar SP, Jim A, Sisodia V. Effects of Palliative Care Training Program on Knowledge, Attitudes, Beliefs and Experiences Among Student Physiotherapists: A Preliminary Quasi-experimental Study. Indian J Palliat Care. 2011;17(1):47-53.

[3] Kumar SP, Saha S. Mechanism-based Classification of Pain for Physical Therapy Management in Palliative care: A Clinical Commentary. Indian J Palliat Care. 2011;17(1):80-6.

[4] Prem V, Karvannan H, Chakravarthy R, Binukumar B, Jaykumar S, Kumar SP. Attitudes and Beliefs About Chronic Pain Among Nurses-Biomedical or Behavioral? A Cross-sectional Survey. Indian J Palliat Care. 2011;17(3):227-34.

[5] Kumar VK, Kumar SP, Baliga MR. Prevalence of work-related musculoskeletal complaints among dentists in India: a national cross-sectional survey. Indian J Dent Res. 2013;24(4):428-38.

[6] Kumar SP, Kumar A. Evidence-based Practice in Chronic Pain: A Multidimensional Biopsychosocial Paradigm is the "Need of the Hour" in Palliative Care. Indian J Palliat Care. 2013;19(2):126-7

[7] Kumar SP, D'souza M, Sisodia V. Interpersonal communication skills and palliative care: "finding the story behind the story". Indian J Palliat Care. 2014;20(1):62-4.

Acknowledgments: Study participants for their whole-hearted participation and contribution.

Disclosure of Interests: None declared

DOI: 10.1136/annrheumdis-2020-eular.196

\section{THU0649-HPR ASSESSMENT OF THE EFFECTIVENESS OF THE EDUCATIONAL PROGRAM FOR PATIENTS WITH RHEUMATOID ARTHRITIS}

M. Salokhiddinov ${ }^{1}$, F. Umarov ${ }^{1} .{ }^{1}$ Tashkent Medical Academy, Tashkent, Uzbekistan

Background: Effective therapy of rheumatoid arthritis (RA) is impossible without the active and competent participation of the patient in this process, which requires educational programs based on the real needs of the patient

Objectives: The purpose of the study was to develop an educational program for patients with RA and evaluate its effectiveness

Methods: The study included 65 patients with RA. 35 patients of the main group were trained in the educational program. Of these, 30 patients made up the control group. The educational program consisted of 4 daily classes of 90 minutes. Initially and after 6 months, the indices DAS28, HAQ, RAPID3 were determined using the MDHAQ questionnaire
Results: After 6 months after training in the main group, the DAS28 index decreased by $1.28 \pm 0.28$ points $(p<0.05)$, HAQ - by $0.65 \pm 0.39(55.2 \%)$ ( $p$ $<0.01)$, RAPID3 - by $4.87 \pm 0.82(45.6 \%)(p<0.01)$, anxiety level - by $0.78 \pm 0.28$ $(52.1 \%)(p<0.05)$, depression - by $0.76 \pm 0.54(43.4 \%)(p<0.05)$, fatigue - by $2.96 \pm 1.21$ points $(42.3 \%)(p<0,05)$, sleep improved by $0.85 \pm 0.34(52.3 \%)$ ( $p<0.05) .6$ months after participating in the educational program, a good response to treatment according to DAS28 according to EULAR criteria was significantly more often recorded $(54.5 \%$ versus $29.0 \%$ in the control group (p $<0.05$ ), and the number of patients noted improvement well-being increased by 9 times $(p<0.01)$. The dynamics in the control group was less pronounced, which determined statistically significant differences between groups for most indicators $(p<0.05)$

Conclusion: The educational program improves functional capabilities, psychological status, helps control the activity of the disease and improves the quality of life of patients with RA

\section{References:}

[1] Chen SY Wang. The Relationship between Physical Function, Knowledge of Disease, Social Support and Self care behavior in Patients with Rheumatoid Arthritis. Journal of Nursing Research. 2007;15:183-191.

[2] Taal E, Rasker JJ, Seydel ER, Wiegman O. Health Status, adherence with health recommendations, self-efficacy and social support in patients with rheumatoid arthritis. Patient Education \& Counseling. 1993;20:63-76.

Acknowledgments: I would like to thank to all my Prof Ahmedov and department of Rheumatology for their sincere support

Disclosure of Interests: None declared

DOI: 10.1136/annrheumdis-2020-eular.622

\section{THU0650-HPR THE USE OF GAMIFICATION TO MOTIVATE HEALTH PROFESSIONALS IN RHEUMATOLOGY TO PARTICIPATE IN BLENDED LEARNING.}

R. Sengewein ${ }^{1}$, P. Steffens-Korbanka ${ }^{2}$, J. Wendler ${ }^{3}$, M. Kieslich ${ }^{4}$, E. Schmok ${ }^{5}$, G. Gauler6. ${ }^{1}$ Humeo GmbH, Düsseldorf, Germany; ${ }^{2}$ Rheumapraxis an der Hase, Osnabrück, Germany; ${ }^{3}$ Rheumatologische Schwerpunktpraxis, Erlangen, Germany; ${ }^{4}$ Heinrich Heine University Düsseldorf, Düsseldorf, Germany; ${ }^{5}$ University of Lübeck, Lübeck, Germany; ${ }^{2}$ Rheumapraxis an der Hase, Osnabrück, Germany

Background: Blended learning is an increasingly popular learning supplement for traditional classroom-based courses in medical education. Once implemented, many factors influence its success. This was demonstrated by Shivetts et al., who concluded that student motivation plays a major role. In particular, if a learner is not self-motivated, e-learning may not represent the best learning environment. ${ }^{1}$ However, gamification methods are known to enhance motivation in medical education and, if used correctly, can overcome this deficit. ${ }^{2}$ For this purpose, a quiz duel was created and used as a blended learning approach for health professional training in rheumatology. We hypothesize that the use of the quiz duel gamification technique improves learners' motivation to successfully complete their blended learning course.

Objectives: To investigate the potential of gamification methods in motivating health professionals to answer multiple choice questions (MCQs) in a pilot blended learning scenario.

Methods: Four hundred and sixty MCQs were developed in accordance with the learning objectives of a certified training course and integrated into a learn ing management system (LMS). As a gamification technique, a duel mode was created. Course participants had access via an individual user account and used personal smartphones. After each answer was provided, the learners received corrective and explanatory feedback, as well as information on how the duel opponent answered. Incorrectly answered MCQs were repeated in further duels.

Information on the number of MCQs answered (1), days learned (2), and learning time spent (3) was collected and analyzed. Each day on which at least one MCQ was answered counted as a learning day per user. The learning time was calculated with $1.5 \mathrm{~min}$ per $\mathrm{MCQ}$ answered. Analysis was performed over a 15-week period (08/19-12/19).

The training event ("RFAplus") was organized by the Rheumatologische FortbiIdungsakademie $\mathrm{GmbH}$ and took place on three weekends in intervals of fou weeks in Germany. The LMS used was Humeo (Humeo $\mathrm{GmbH}$ ). All users agreed to the terms and conditions of use and data protection before participating in the blended learning intervention.

Results: Nineteen female health professionals in rheumatology participated in the study. The mean age of participants was 43.5 years (range, 21-60 years). The $460 \mathrm{MCQs}$ were answered 20,397 times, with $1039 \mathrm{MCQs}$ per 